\title{
Strategic Planning and Conference Planning Update
}

\author{
Kay A. Persichitte ${ }^{1}$
}

Published online: 11 March 2016

(C) Association for Educational Communications \& Technology 2016

Your AECT leadership has been busy with a number of initiatives related to our strategic plan and planning for the 2016 Conference! Division leadership, the AECT Board of Directors, the ect Foundation Trustees, the AECT Staff, and many of our Committees have been actively engaged in efforts to:

- Implement the member growth strategy,

- Update current member data as one element of our member retention strategy,

- Move forward with Division plans driven by the ongoing division-level meetings with Brent Slinkard,

- Support leadership development across all segments of our membership and all areas of the organization,

- Advance the scholarship and research of our members (e.g., develop special editions for our journals, prepare new Books \& Briefs, participate in international and regional research symposia),

- Expand our international collaborations and engagement,

- Improve our recognition of the volunteerism culture that sets AECT apart from so many other professional organizations... and many more.

As 2016 launched, we adopted a formal policy for AECT sponsorship of international symposia. To manage the increasing number of such requests and to assure that the process for approval of these partnerships receives special attention, we established the International Symposia Coordination Team (ISCT). The three-member team (Feng-Qi Lai, Ana Donaldson, and Dirk Ifenthaler) is making wonderful progress in coordinating these activities and sharing accurate information with all of us.

I close this note with a sincere THANK YOU to each and every one of you who shares your time, your resources, your expertise, and your connections to make AECT better! As we make final agenda revisions for the upcoming Summer Leadership and Board Meeting (July 18-21 in Bloomington, IN), please feel free to contact me (kpersi@uwyo.edu) if you have ideas for leadership to consider.

Wising you a great summer,

\section{Kay}

\section{AECT President}

Kay A. Persichitte is a Professor in Instructional Technology at the University of Wyoming in Laramie, WY and the current President of the Association for Educational Communications and Technology. She may be reached via email at: kpersi@uwyo.edu.
Kay A. Persichitte

kpersi@uwyo.edu

1 University of Wyoming, Laramie, WY, USA 